\title{
Development characteristic and formation mechanism analysis of collapse sinkholes in Wugaishan town, Chenzhou city, Hunan province, China
}

\section{Zongyuan Pan ( $\square$ zypan@karst.ac.cn )}

institue of karst geology https://orcid.org/0000-0002-0741-2695

\section{Xuejun Chen}

Guilin University of Technology

Xin Yang

Guilin University of Technology

\section{Yu Song}

Guilin University of Technology

\section{Rulong Ban}

Guilin University of Technology

Mingzhi Zhang

Guilin University of Technology

\section{Research Article}

Keywords: Cover collapse sinkhole, Development characteristic, Affecting factor, Groundwater level, Formation mechanism

Posted Date: March 4th, 2021

DOI: https://doi.org/10.21203/rs.3.rs-271268/v1

License: (9) This work is licensed under a Creative Commons Attribution 4.0 International License. Read Full License 


\section{Abstract}

The cover collapse sinkholes occurred and concentrated in Wugaishan town, Chen zhou city since 1996. The results are combined with results of site investigation, geophysical prospecting and in situ groundwater monitoring data, allowing the development characteristics and formation mechanism of surficial collapse incidents to be summarized. Collapse sinkholes are significantly active in recent years and mostly develop in the rainy season ranging from April to June and generally show a zonal distribution along the topography of study area from SW to NE. $92.31 \%$ of total collapse events occurred in the thickness of overburden material ranged from 0 to $15 \mathrm{~m}$, which indicated that overlying material less than $15 \mathrm{~m}$ was easier to collapse. The results show that collapse sinkholes have strong relationship with characteristic of overburden material, which sharply decrease in internal physical and mechanical property of bottom layer. Furthermore, substantial cavities formed within bedrock are the best transport channels and storage spaces for the unconsolidated material, especially under the condition of dynamic undulation of groundwater level. The formation mechanism of collapse sinkhole is divided into three types: infiltration erosion, coupling air implosion with vacuum cavitation and saturation erosion. Each formation mechanism is related to changes of groundwater level. When groundwater level rose above the soil-bedrock interface, saturated subsoil were easier to disintegrate into small particles and migrate downward as the vertical seepage of groundwater. The hydraulic gradient increased and became the predominant factor for the development of soil cavity as groundwater level dropped below the soilbedrock interface. Moreover, when groundwater level sharply surged up at the relative sealed environment, the upward erosion roof of cavity would be more likely to collapse by the entrapped air blasting.

\section{Full Text}

Due to technical limitations, full-text HTML conversion of this manuscript could not be completed. However, the latest manuscript can be downloaded and accessed as a PDF.

\section{Figures}




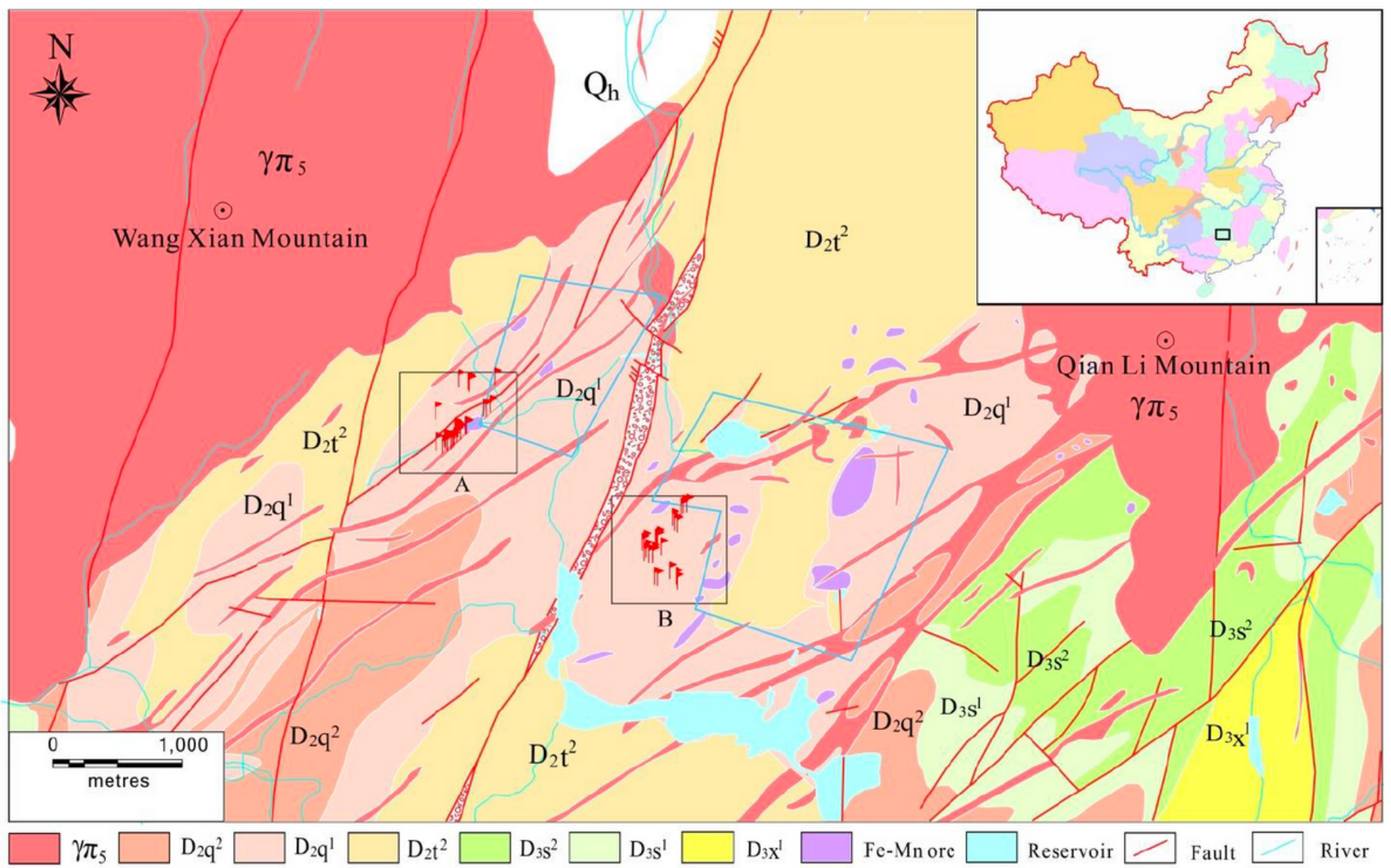

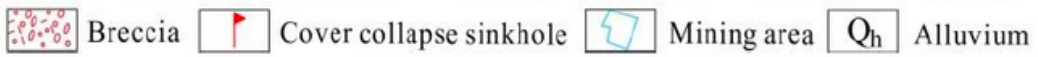

\section{Figure 1}

Location and geological map of the study area. A refer to Shuangyuanchong village. B refer to Fengshuxia village. Note: The designations employed and the presentation of the material on this map do not imply the expression of any opinion whatsoever on the part of Research Square concerning the legal status of any country, territory, city or area or of its authorities, or concerning the delimitation of its frontiers or boundaries. This map has been provided by the authors.
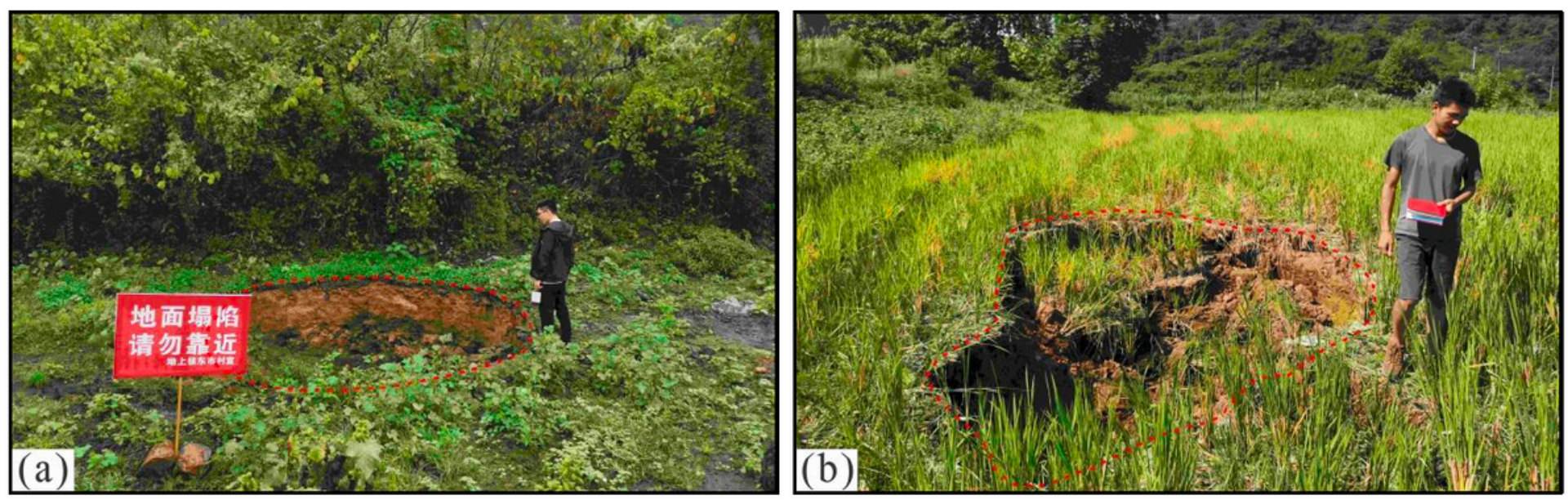

Figure 2 
Cover collapse sinkholes of different sizes in study area. a Collapse sinkhole $3 \mathrm{~m}$ in diameter at a dried up pond, right of the photo is north. $b$ Irregular sinkhole in Fengshuxia village (long axis and short axis is $3 \mathrm{~m}$ and $1.5 \mathrm{~m}$, respectively), top of the photo is north.
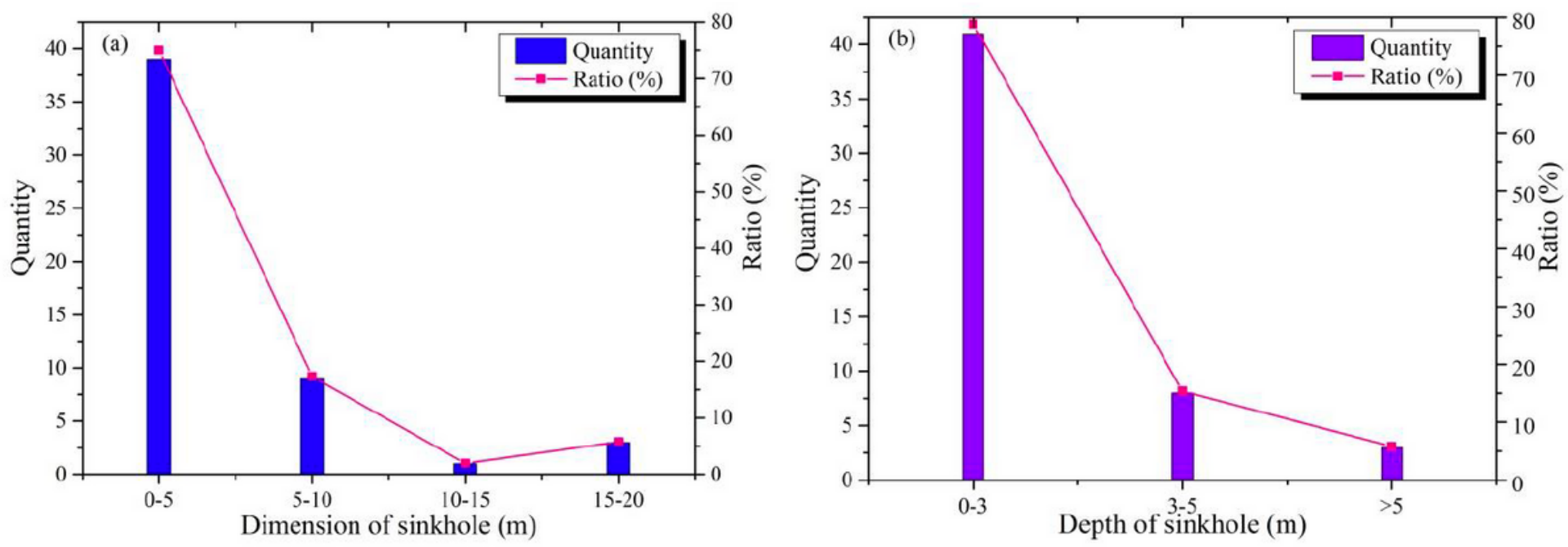

Figure 3

Morphology characteristic of cover collapse sinkhole in study area. a Plane size distribution of cover collapse sinkhole. b Depth distribution of cover collapse sinkhole.
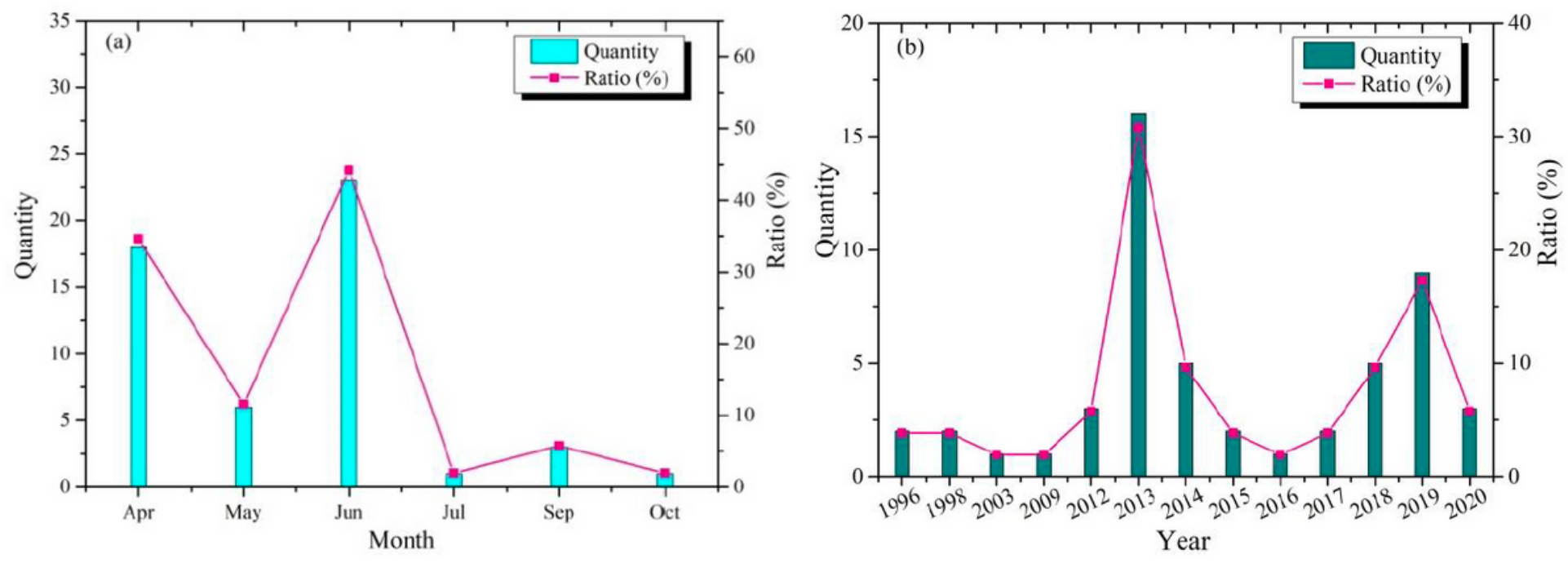

Figure 4

Temporal occurrence of cover collapse sinkhole. a Monthly occurrence of cover collapse sinkhole. b Annual occurrence of cover collapse sinkhole. 

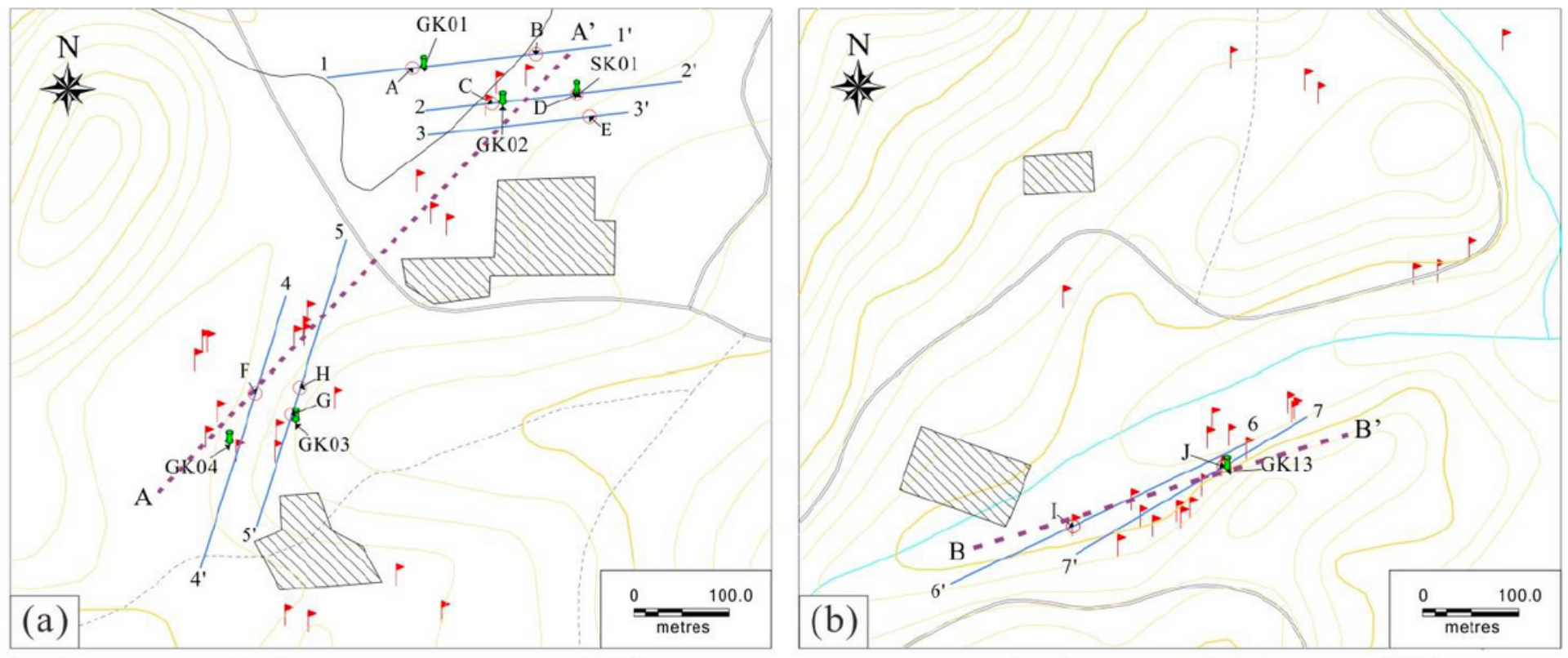

Contour line $\square$ Cover collapse sinkhole $\square$ Geophysical prospecting line $\square$ Borehole $\square$ Outlier $\&$ Highway Footpath $\$$ Resident house $\ldots$ Cross section line

\section{Figure 5}

The layout of geophysical prospecting work in study area. a Location of geophysical prospecting line in Fengshuxia village. b Location of geophysical prospecting line in Shuangyuanchong village. Note: The designations employed and the presentation of the material on this map do not imply the expression of any opinion whatsoever on the part of Research Square concerning the legal status of any country, territory, city or area or of its authorities, or concerning the delimitation of its frontiers or boundaries. This map has been provided by the authors. 

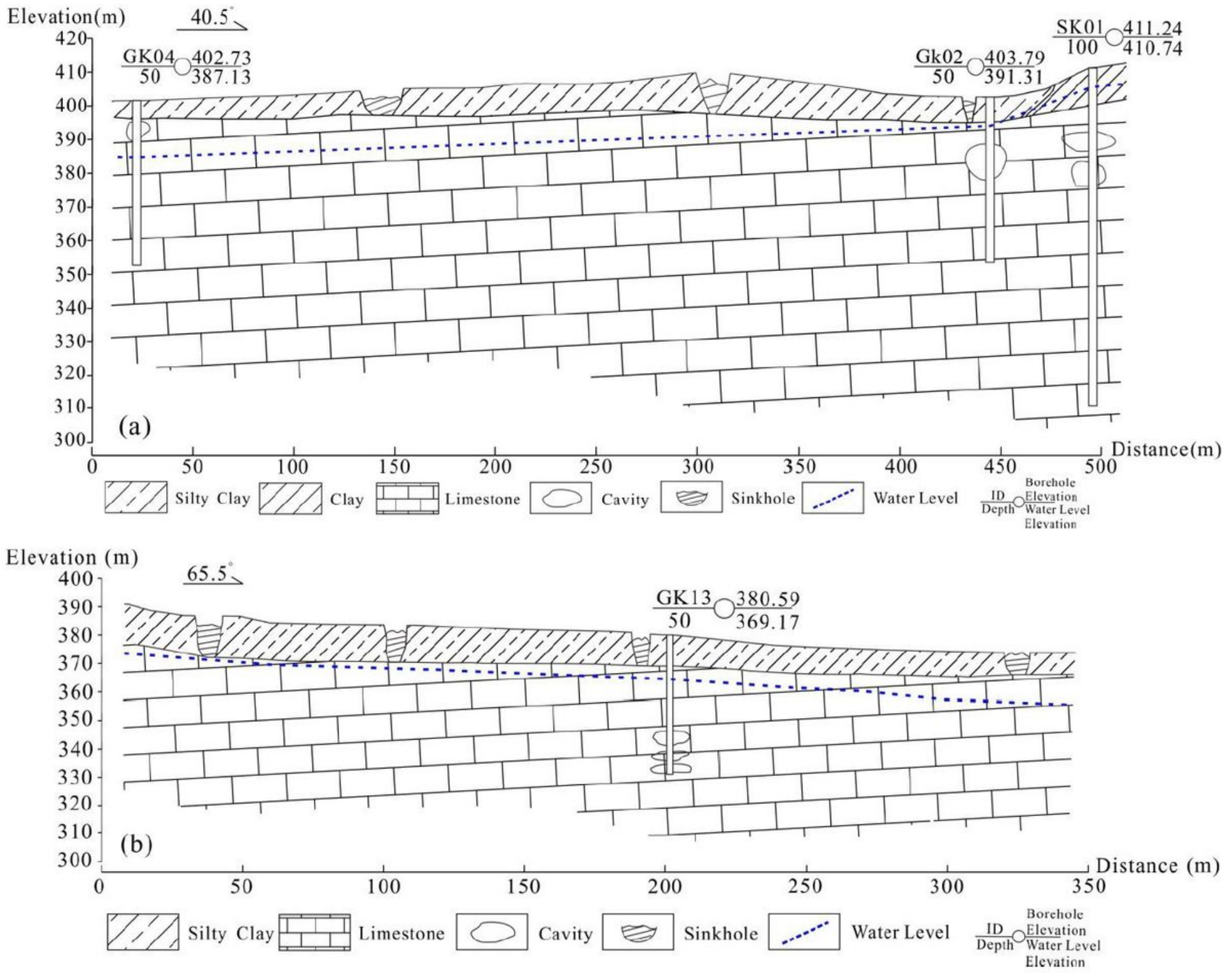

\section{Figure 6}

The longitudinal cross section of hydrogeology in study area. a Cross section of line A-A' in Fengshuxia village. b Cross section of line B-B' in Shuangyuanchong village.

Elevation $(\mathrm{m})$

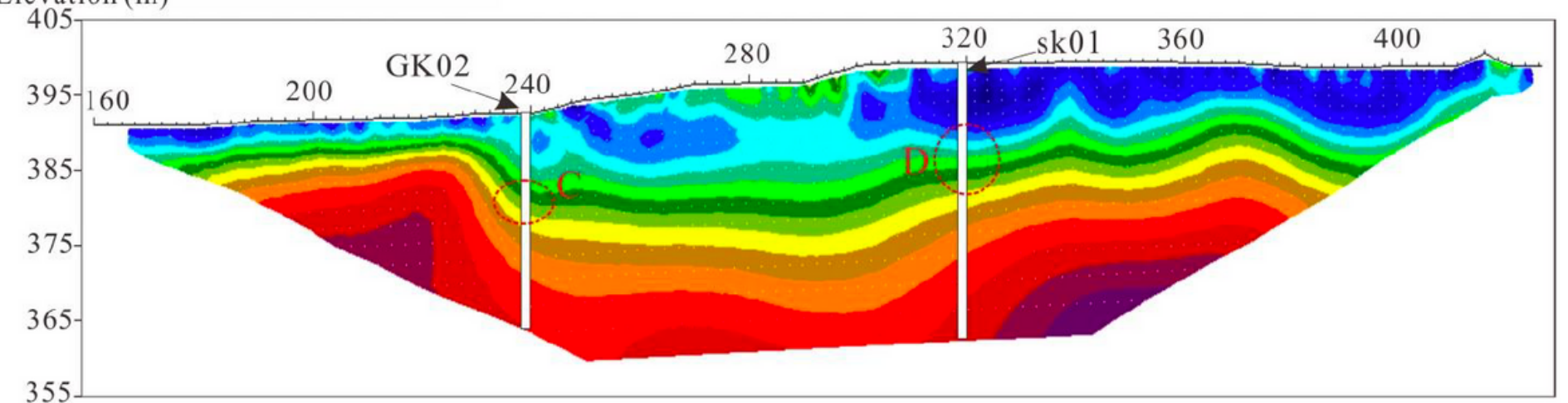

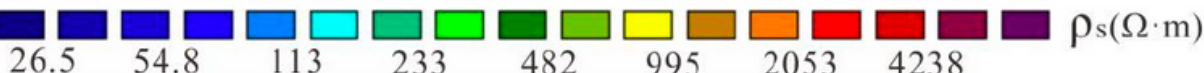


Figure 7

High density tripolar electrical sounding resistivity inversion map of line 2.

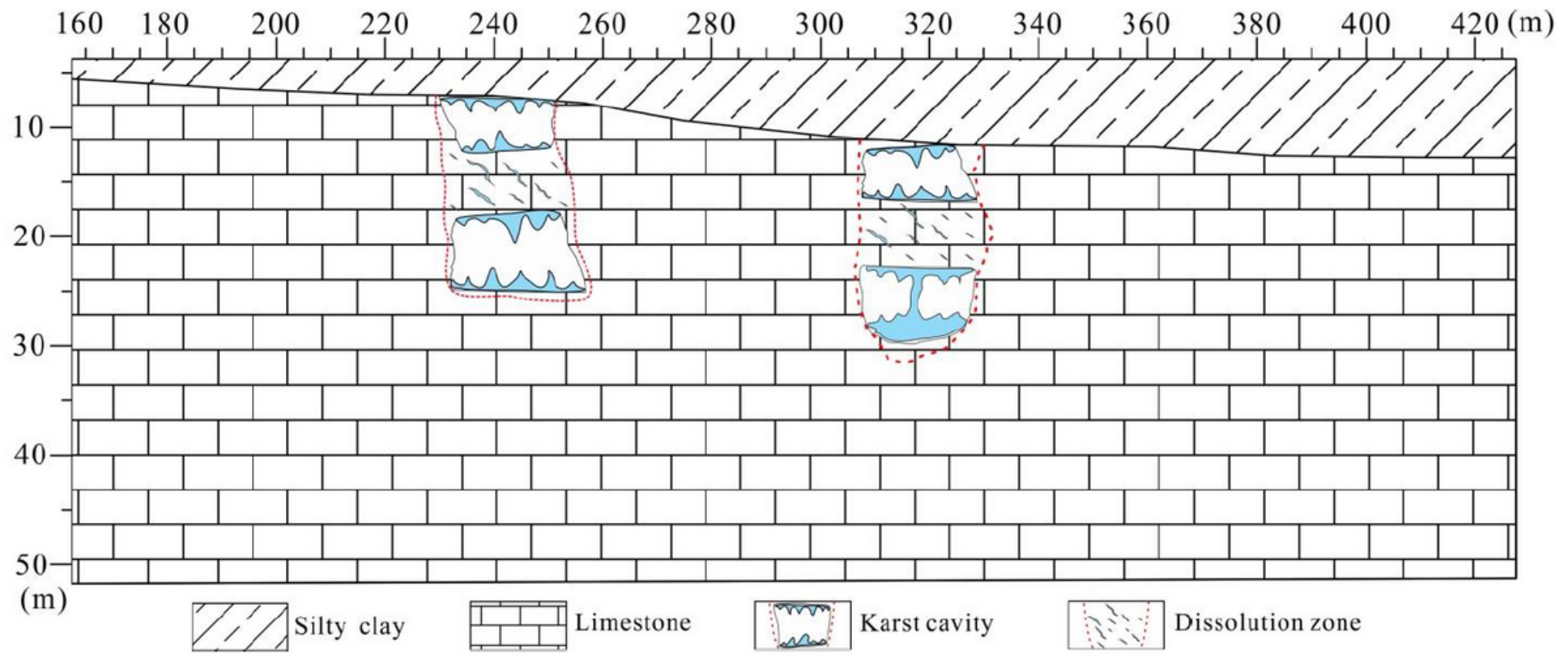

Figure 8

The comprehensive geological interpretation map of line 2 . 

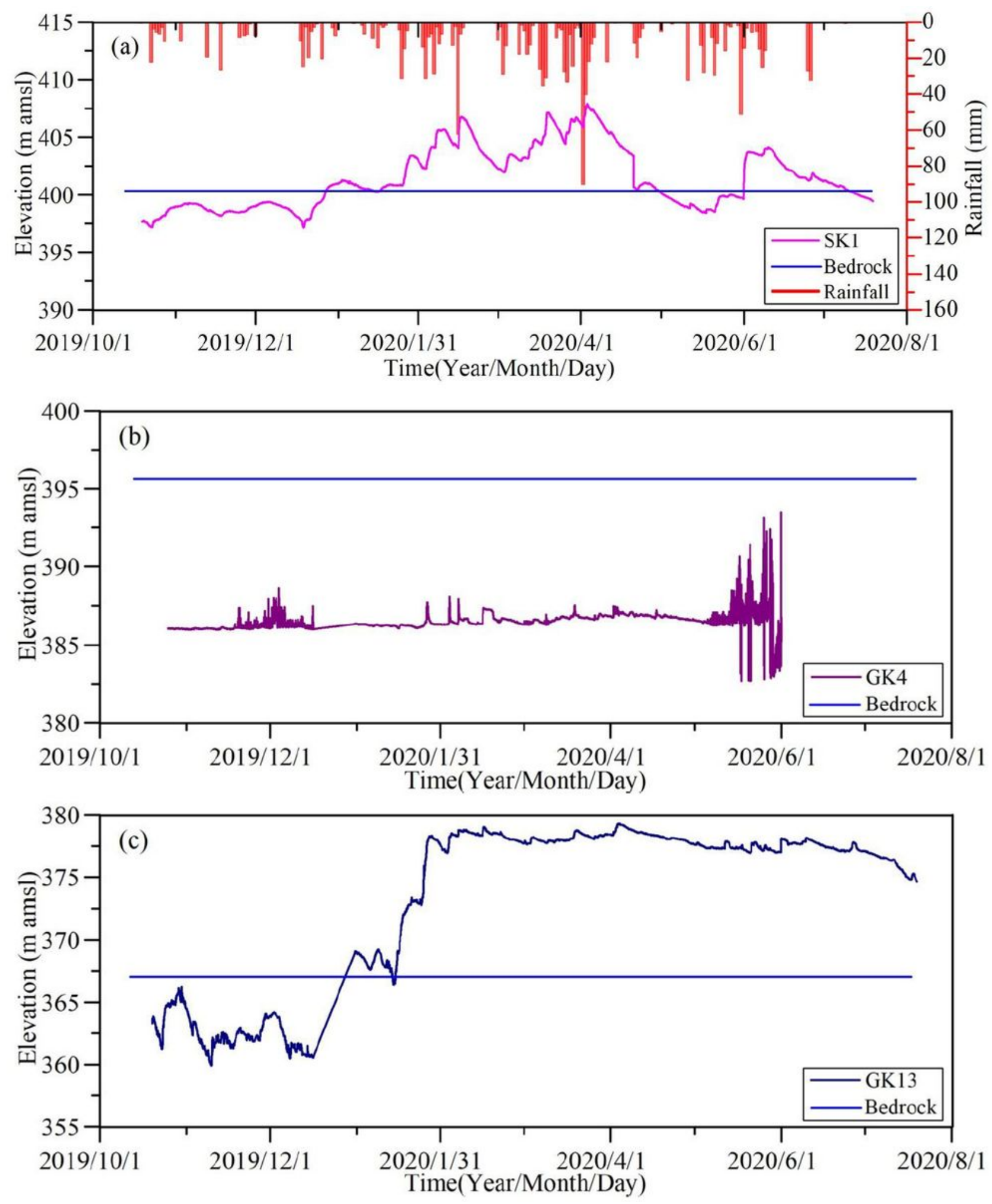

Figure 9

Variations of groundwater levels from $10 / 19 / 2019$ to $7 / 19 / 2020$ 


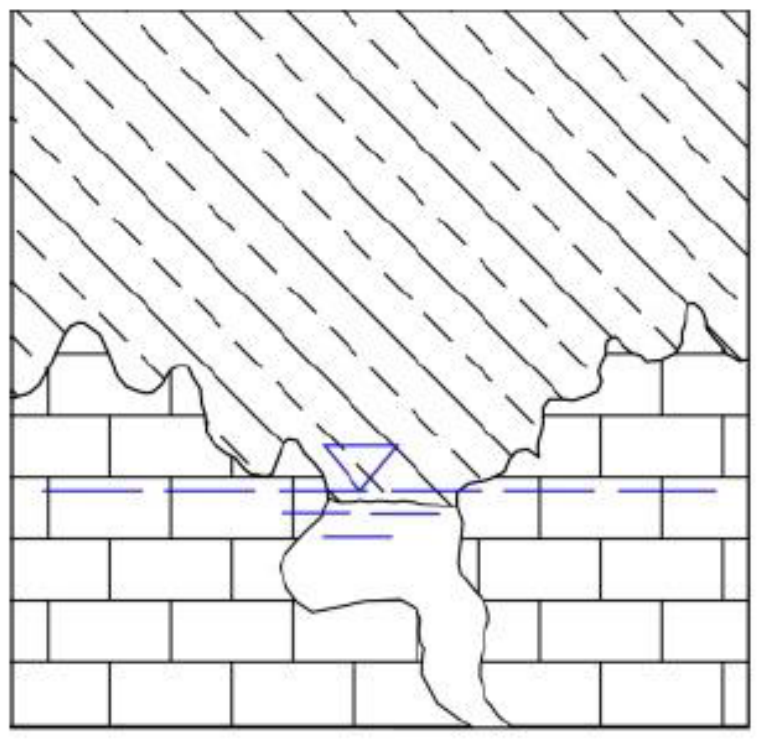

(a)

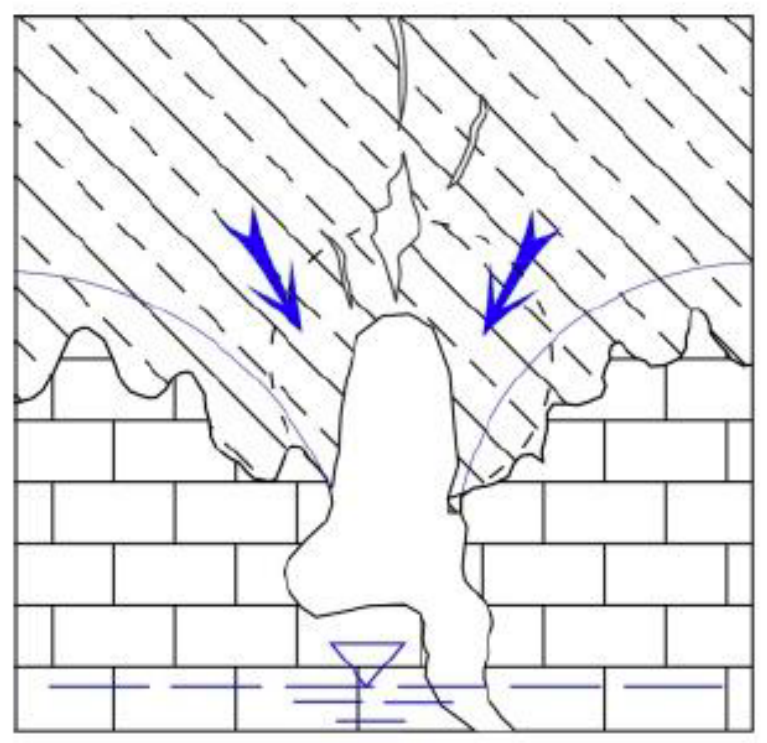

(c)

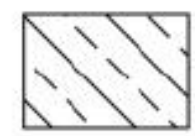

Siltyclay

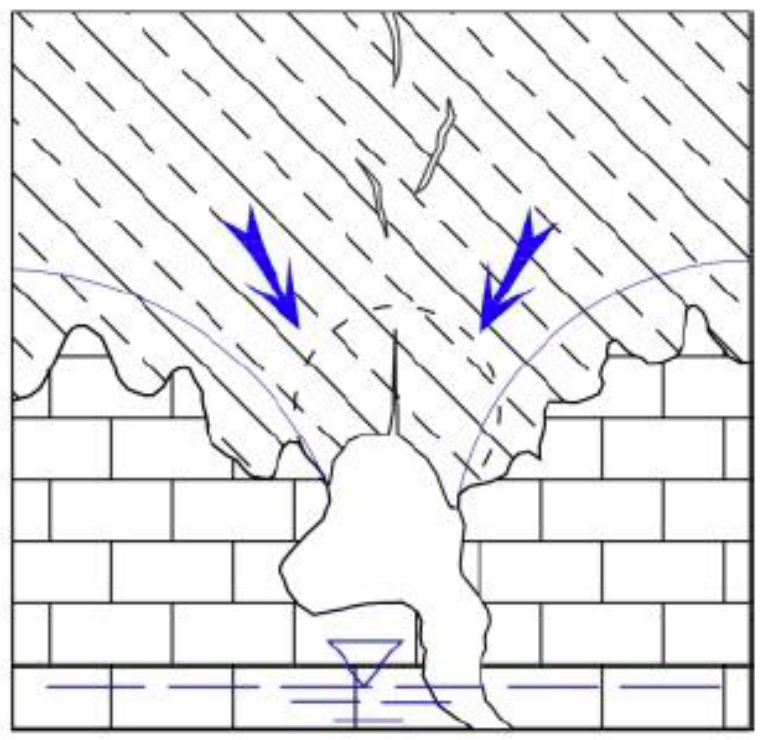

(b)

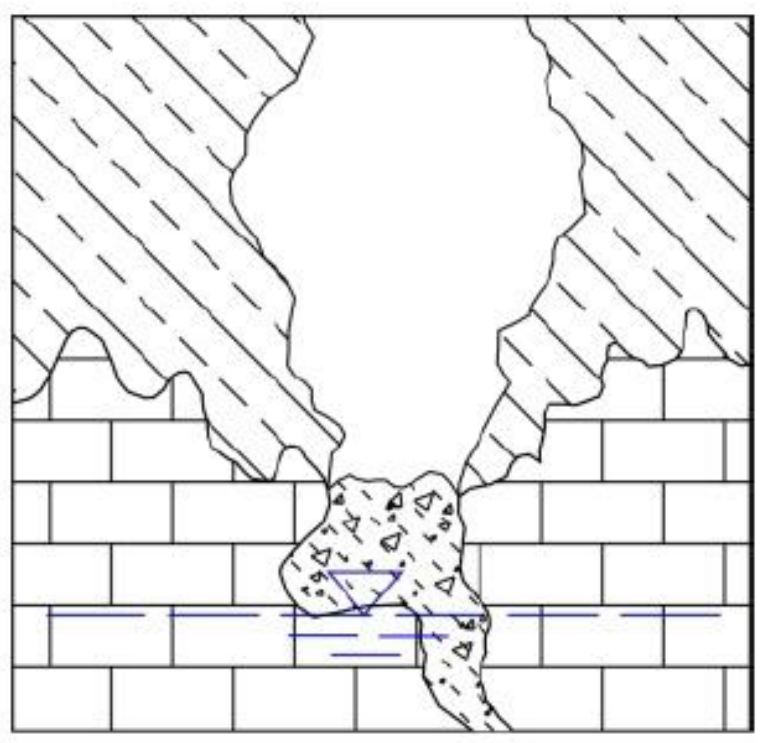

(d)

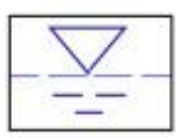

多文文

Collapsed soil

\section{Figure 10}

Schematic drawing of infiltration erosion in sinkhole development. a Groundwater level fluctuates around the soil-bedrock interface. b Soil cavity forms overlain the bedrock when groundwater level declines. c Soil cavity begins to propagate upwards when surface water infiltration. $d$ Collapse sinkholes occur when internal cohesion and friction can't support soil cavity. 


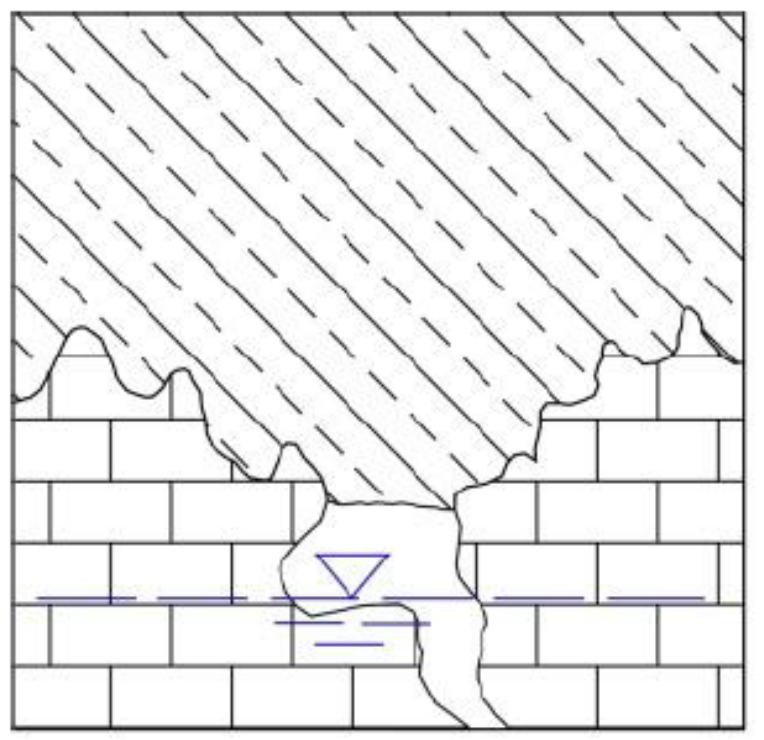

(a)

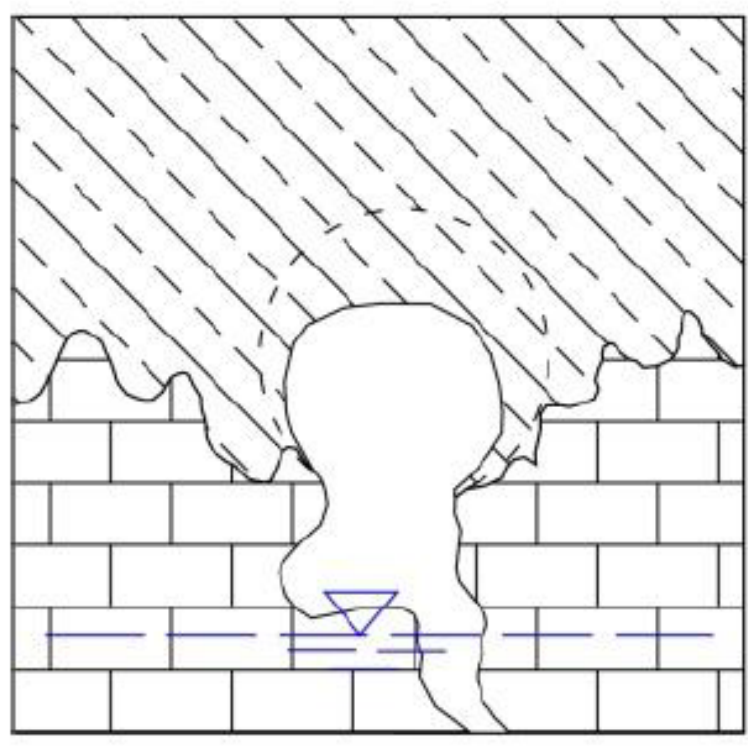

(c)

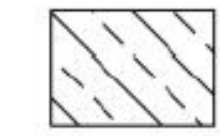

Siltyclay

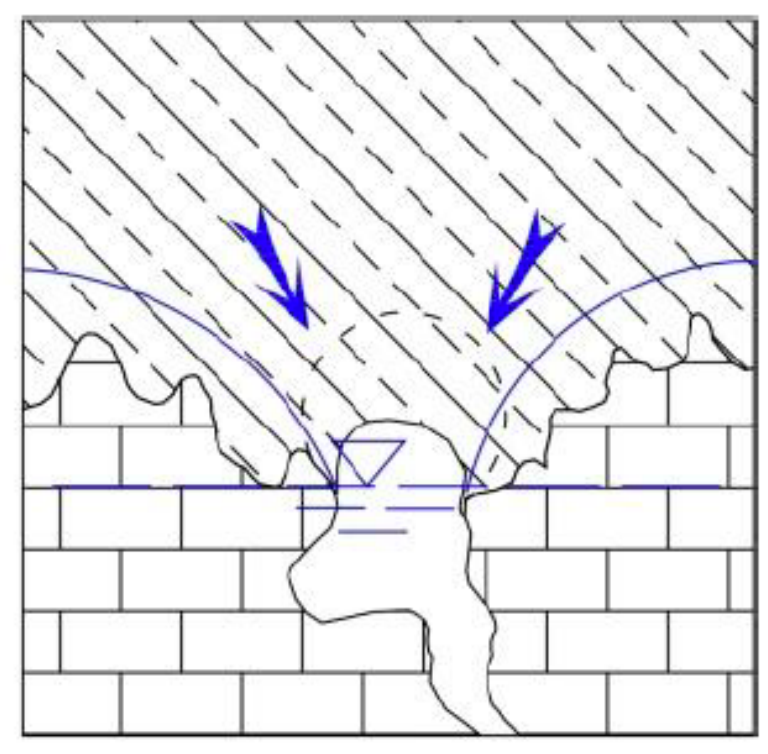

(b)

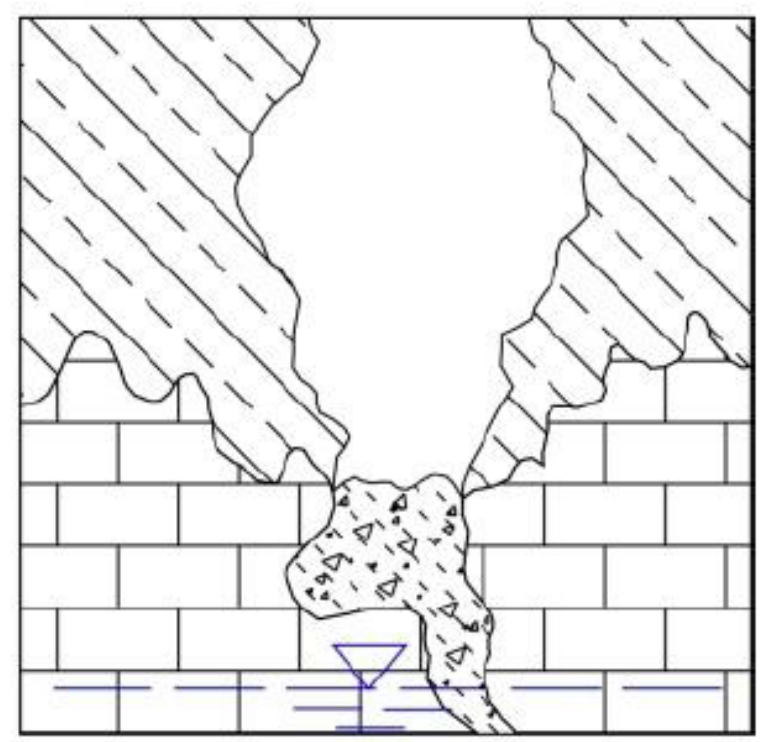

(d)

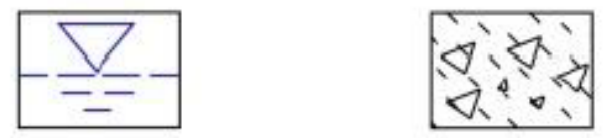

Water level Collapsed soil

\section{Figure 11}

Schematic drawing of groundwater-air dynamic variation in sinkhole development. a Groundwater level is within the karst conduits that underlying the overburden materials. b Groundwater level drastically increases by the infiltration of surface water result in implosion of entrapped air. c Groundwater level declines causing vacuum cavitation that accelerating soil cavity propagate upwards. d Soil cavity eventually collapses due to groundwater level goes up and down repeatedly. 


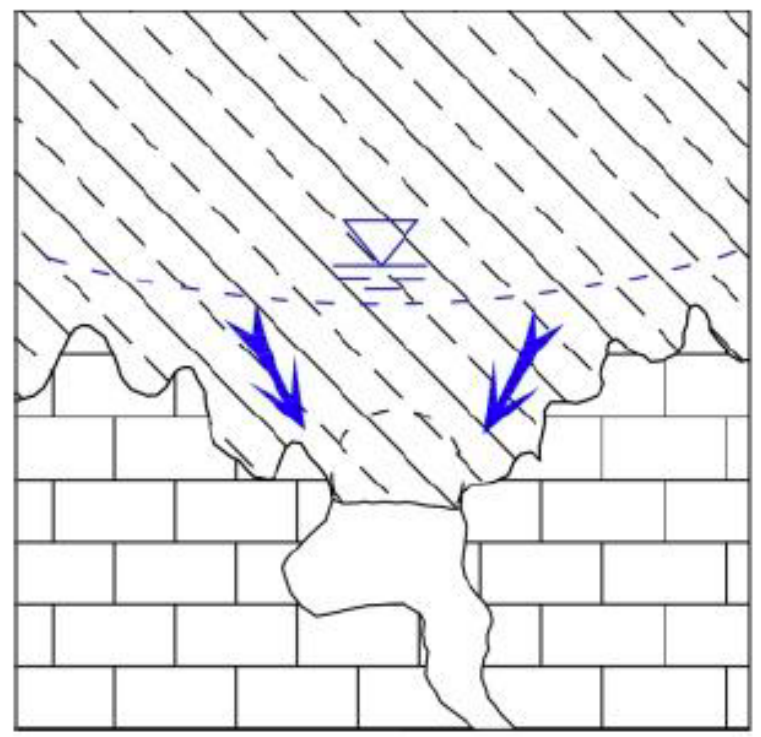

(a)

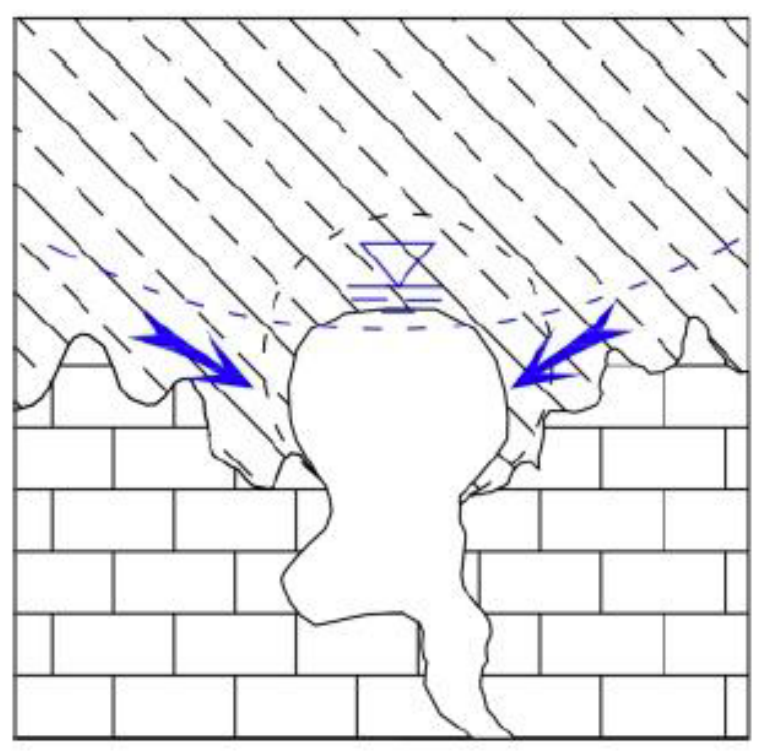

(c)

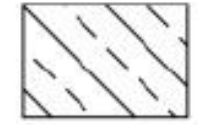

Siltyclay

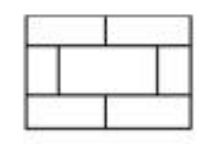

Limestone

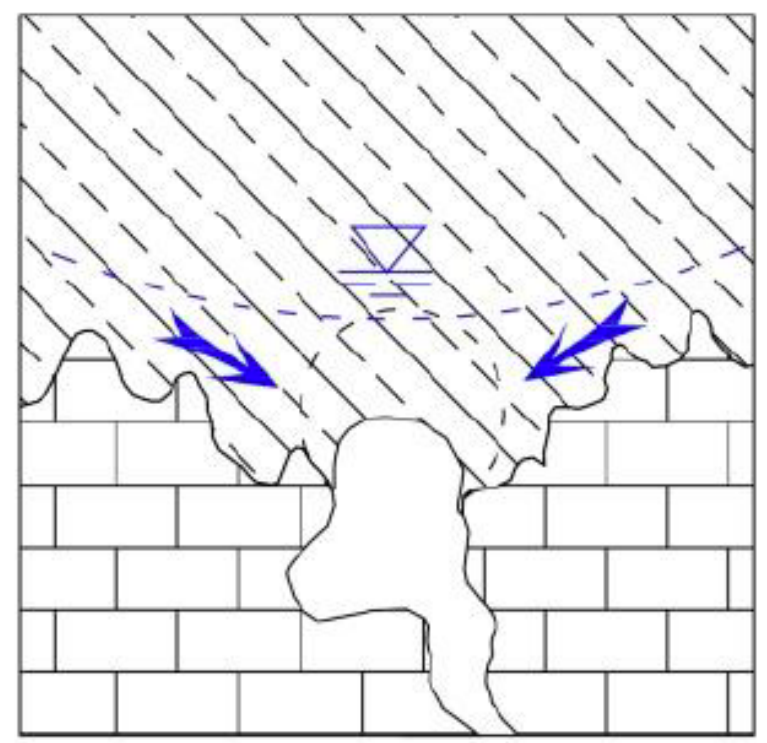

(b)

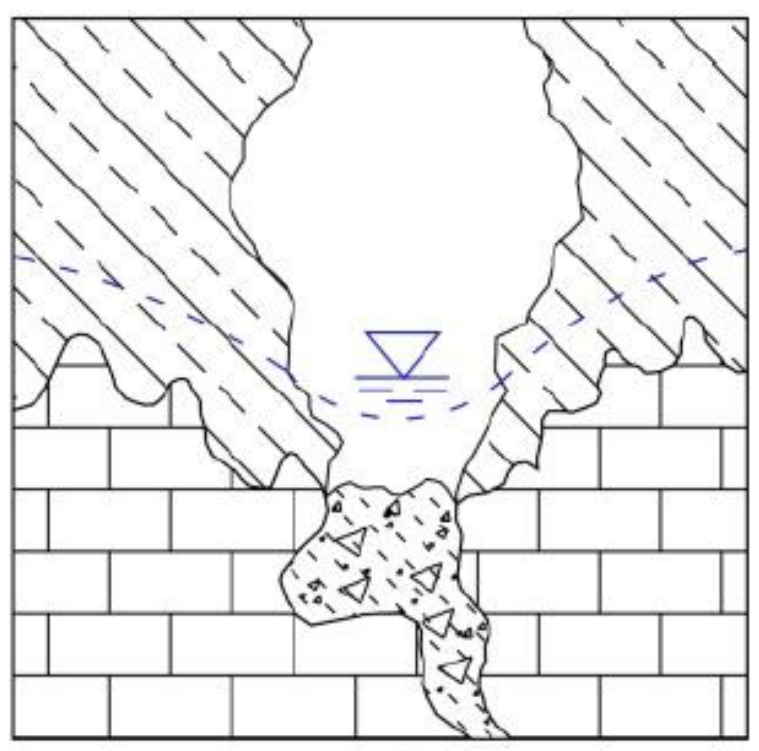

(d)

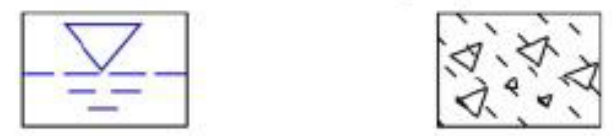

Water level Collapsed soil

Figure 12

Schematic drawing of subsoil erosion in sinkhole development. a Groundwater level rise above the soilbedrock interface. b Saturated subsoil were easier to disintegrate into small particles and migrate downward as the vertical seepage of groundwater. c Soil cavity begins to enlarge as the subsoil erosion continuously proceeding. $\mathrm{d}$ Collapse incident occur as the soil cavity expanding to the certain extent. 